\title{
Adherence to treatment and health perceptionsamong youth with diabetes mellitus in Portugal
}

\author{
Henrique Pereira*, Fábia Alves, Samuel Monteiro, Rosa Marina Afonso, Graça Esgalhado and Manuel Loureiro \\ Department of Psychology and Education, Faculty of Social and Human Sciences, University of Beira Interior, Estrada do Sineiro, S/N 6200 Covilha, Portugal
}

\begin{abstract}
Few studies concerning the relationship of diabetes treatment with health perceptions among youth diagnosed with diabetes mellitus in Portugal have been conducted. Therefore, the aims of this research are to evaluate the levels of treatment adherence in a sample of diabetic youth, in order to measurethe relationship between the perception of health status and treatment adherence levels.Furthermore, the study also intends to identify differences according to age, gender, parental support, thesupport of friends, and medical support.68 youth participated in this study ( $45.6 \%$ male, $54.4 \%$ female).The mean age of the participants was 18.74 years (SD= 4.18) and $95.6 \%$ were diagnosed with type-1diabetes. The study used a socio-demographic questionnaire, the 36 Item Short-Form Health Survey, in addition tothe Summary of Diabetes Self-care Activities Measures (SDSCA) as measurement instruments. Regarding the adherence to behavioral prescriptions, results showed a high level of compliancewith the recommended instructionsamong all participants. Significant differences for several dimensions of adherence were found when comparing groups defined by gender, age, family support, friends support, and medical support. Correlational analyses show that the perception of general health is related to the levels of adherence to diabetes therapy. The implications of these results are discussed.
\end{abstract}

\section{Introduction}

Diabetes Mellitus (DM) is one of the leading chronic diseasesof childrenand adolescents.It affects 1.82 out ofevery 1,000 young people in the United States [1] and $0.16 \%$ of the Portuguese population aged from 0 to 19 years of age [2]. Although the majority of youth with diabetes have type-1diabetes, type-2 diabetes has also been reported. Individuals with DM are typicallyplaced on a strict and complex maintenance regimen that involves regular administrationof insulin through injections, attention to diet and exercise, and monitoringglucose levels, while making the appropriate treatment adjustments. Although self-care is oftenchallenging for all age groups, a significant number of children and adolescentsfail to adhere to physician directives and do not receive adequate self-care $[3,4]$.

The goal of treatment is to maintain optimal glycemic control so that hypo and hyperglycemic episodes are avoided. Excessively low or high levels of blood glucose are contraindicated because they can substantially increase the risk of serious medical complications, including retinopathy, nephropathy, neuropathy, heart disease, limited joint mobility, and even a shortened life span [5]. The number and complexity of the different tasks involved in managing DM can be overwhelming, even for the most competent patient. This is especially apparent for adolescents, who are concurrently coping with various developmental tasks ranging from dramatic physical changes to increasing peer pressure [6]. Concerns about adolescents being especially vulnerable to poor adherence have been largely generated by empirical research,which reveals that children with diabetes tend to show a precipitous decline in glycemic control as they enter adolescence. Several variables have been linked to poor adherence, such as a lack of parental involvement, a lack of peer support, external locus of control, a lack of self-efficacy,and negative health beliefs $[7,8]$.

Some studies explored dietary adherence, namely eating behaviors, consuming sufficient macronutrients, and following dietary recommendations. Rates of adherence to recommended eating behaviors ranged from $21 \%$ to $95 \%$ [9]. Other studies explored the importance of intrapersonal variables, such as conscientiousness, neuroticism personality domains, and one or more self-reported adherence behaviors [10]. Quantitative research into barriers to treatment adherence has identified a range of factors including: costs and access to treatments, the complexity and demands of the treatment regimen, and a lack of social support and depression [11]. Research into promoting treatment adherence has found that the most effective interventions are complex and include combinations of more convenient care, information, reminders, specific behavioral change techniques $[12,13]$, and the involvement of patients in the decisionmaking process [14].

Regarding the quality of life among youth with DM, most studies emphasize the importance of family factors (family support and parental coping), adolescents and parents' illness representations [15], the impact of treatment, and depression or difficulty managing the disease [16] as mediators of quality of life.However, other studies demonstrate that age, gender, a high BMI, poor metabolic control, and the intensity of treatment did not influence the quality of life of children with diabetes [17].

Fewexisting studies explore the relationship between the perception of health status and adherence to diabetes treatment among young people. Thus, we sought to examine whether better health perceptions

Correspondence to: Henrique Pereira, Department of Psychology and Education, Faculty of Social and Human Sciences, University of Beira Interior, Estrada do Sineiro, S/N 6200 Covilha, Portugal, Tel: +351 275319 700; E-mail: hpereira@ubi.pt

Key words: adherence, health perceptions, diabetes mellitus, youth

Received: April 20, 2015; Accepted: May 24, 2015; Published: May 26, 2015 
lead to increased or decreased levels of adherence to treatment in this population. The following specific objectives were outlined:to evaluate the levels of adherence to treatment in diabetic young people; to evaluate the relationship between the perception of health status and the levels of adherence to treatment; andto identify differences according to age, gender, parental support, friends support, and medical support.

\section{Materials and methods}

\section{Participants}

A convenience sample of Portuguese youth with diabetes between 11 and 30 years oldwas selected to participate in a cross-sectional study. The study involved 68 youth, of whom 31 were male $(45.6 \%)$ and 37 were female (54.4\%). The mean age of the sample was 18.74 years $(S D=4.18)$. In order to better describe the participants and enhance the analysis of the results, the sample was divided into two groups. The first group consisted of subjects between 11 and 18 years old (adolescents),while the second group was composed of subjects ranging from 19 to 28 years old (young adults). All participants attend school or university, and the majority $(60.3 \%)$ stated that they did not practice any type of extracurricular activity.

Regarding the type of diabetes, the vast majority of participants (95.6\%) suffer from type-1 diabetes. The average age of diagnosis was 13.24 years $(\mathrm{SD}=5.11)$. Data on the age when participants began treatment was similar to the age of diagnosis, with participants beginning treatment at 13.21 years of age $(\mathrm{SD}=5.14)$ on average. Regarding the treatment of diabetes, it was found that $95.6 \%$ of all participants use insulin to treat diabetes, $2.9 \%$ use pills, and $1.5 \%$ use only dietary recommendations.

In regard to the difficulties experienced with treatment, we found that $58.8 \%$ of youth claim to have difficulty following the recommended dietary prescriptions for diabetes.Only 25\% say that they have difficulties with physical exercise, and the majority of the study participants $(77.9 \%)$ claim that they experience some difficulties with their treatment.

\section{Instruments}

The socio-demographic questionnaire aimed to collect essential information for the study, such as age, sex, educational level, socioeconomic status, and the practice of extracurricular activities. This questionnaire also included questions concerning the type of diabetes, the age of diagnosis, the type of treatment, the age of participants when starting diabetes treatment, any specific difficulties with treatment, and the supportreceived from significant others.

\section{Item Short-Form Health Survey}

The 36-Item Short Form Health Survey (SF-36) is a tool used to facilitate administration and understanding, and allowsfor the generic evaluation of quality of life [18]. It is an instrument consisting of 36 items grouped into eight dimensions: functional capacity (limitations in usual activities due to health issues), physical aspects (limitations in physical activities due to health problems), pain (physical pain), general health (perception that the subject has of his/her health in general), vitality (energy and fatigue), social aspects (limitations in usual activities due to physical or emotional problems), emotional aspects (limitations in usual activities due to emotional problems), and mental health (psychological distress and well-being). The final score of the dimensions is obtained from the sum of the corresponding items and is transformed into a percentage, where $0 \%$ corresponds to worse general health status and $100 \%$ to better health status.

\section{Summary of diabetes self-care activities measures (SDSCA)}

The SDSCA was built with the purpose of evaluating the adherence to self-care activities in diabetic patients [19] andis the most widely used instrument in research on this topic [20]. In total, the scale consists of 19 items, and is parameterized utilizing the number of days per week, where participants indicate the weekly frequency of various activities. Thus, the score ranges from 0 to 7 for each item, taking into account the indicated weekly frequency. The items are grouped into six dimensions, namely: diet, exercise, foot care, glycemic control, drug treatment, and smoking.A Portuguese version of the SDSCA was used in this study (Cronbach's $\alpha=0.81$ ) [21].

\section{Procedures}

Before collecting the data, the instruments were subjected to a pretest with 10 subjects ( 5 female and 5 male) in order to check for possible flaws, ambiguities, or incorrect questions. Parallel to this process, initial contact was made with a General Hospital from the National Portuguese Health Service and the Association of Young Diabetics of Portugal, in order to get permission from these institutions to collect data. The questionnaires were made available in print, and all ethical guidelines were met, namely informed consent and confidentiality. The questionnaires collected in the selected Hospital and in the Association were delivered together with the informed consent form and the completed questionnaires were returned via the use of a sealed envelope. 75 questionnaires were collected, but 7 were eliminated due to incorrect completion.

\section{Results}

Regarding the adherence to behavioral prescriptions, the results showed that compliance with the recommended instructions was as follows: $75 \%$ (51) say that they follow a restricted diet for diabetes, $41.2 \%$ (28) report physical activity, and $54.4 \%$ (37) take care of their feet. Regarding adherence to glycemic control, it was found that most respondents $80.9 \%$ (55) show high levels of adherence to this practice. As for smoking, results indicate that only 12 participants (17.6\%) smoke. Finally, concerning the adherence to medication (insulin), virtually the entire sample (95.6\%) demonstrates good adherence to this aspect of diabetestreatment.

In order to compare differences in the adherence to treatment and behavioral practices between age groups (younger and older youth), the non-parametric Mann-Whitney U test was used. No statistically significant differences were found for the five dimensions of adherence, except for smoking. Younger participants were found tosmoke less, thus revealing higher levels of adherence when compared with older participants $(\mathrm{U}=469, \mathrm{~W}=1030$; $\mathrm{p}=0.04)$ (Table 1).

Table 2 shows the results for the correlation analysis between health perception levels and adherence. Thus, in regard to diet, significant and positive results were obtained concerning functional ability $(\mathrm{r}=0.24$; $\mathrm{p}<0.05)$, general health $(\mathrm{r}=0.49, \mathrm{p}<0.001)$, vitality $(\mathrm{r}=0.47 ; \mathrm{p}<0.001)$, social aspects $(r=0.03 ; p<0.05)$, emotional aspects $(r=0.25 ; p<0.05)$, and mental health $(\mathrm{r}=0.34 ; \mathrm{p}<0.001)$. Therefore, it can be assumed that as we increase the levels of functional capacity, general health, vitality, social and emotional aspects, and mental health, thiswill result in increased adherence to the dietary recommendations for diabetes patients,

As for exercise, significant results were obtainedin relation to functional ability $(r=0.25 ; \mathrm{p}<0.05)$ and vitality $(\mathrm{r}=0.34 ; \mathrm{p}<0.001)$. Thus, the frequency of exercise increases with increased functional capacity and vitality. 
Table 1. Adherence results grouped by age, gender, parental support, friends support, and medical support.

\begin{tabular}{|c|c|c|c|c|c|c|c|c|c|c|c|c|c|}
\hline & & Diet & $\mathbf{U} ; \boldsymbol{p}$ & $\begin{array}{l}\text { Physical } \\
\text { activity }\end{array}$ & $\mathrm{U} ; \boldsymbol{p}$ & $\begin{array}{l}\text { Glycemic } \\
\text { control }\end{array}$ & $\mathrm{U} ; \boldsymbol{p}$ & Foot care & $\mathrm{U} ; \boldsymbol{p}$ & Smoking & $\mathrm{U} ; \boldsymbol{p}$ & $\begin{array}{c}\text { Insulin } \\
\text { administration }\end{array}$ & $\mathbf{U} ; p$ \\
\hline \multirow[t]{2}{*}{ Age } & Younger & 35.23 & \multirow{2}{*}{$552 ; 0.68$} & 32.16 & \multirow{2}{*}{$495 ; 0.24$} & 34.20 & \multirow{2}{*}{$567 ; 0.85$} & 33.49 & \multirow{2}{*}{$542 ; 0.61$} & 37.59 & \multirow{2}{*}{$469 ; 0.04 *$} & 36.00 & \multirow{2}{*}{$525 ; 0.05^{*}$} \\
\hline & Older & 33.73 & & 36.98 & & 34.82 & & 35.58 & & 31.23 & & 32.91 & \\
\hline \multirow[t]{2}{*}{ Gender } & Male & 33.13 & \multirow{2}{*}{$531 ; 0.49$} & 34.76 & \multirow{2}{*}{$565 ; 0.90$} & 33.32 & \multirow{2}{*}{$537 ; 0.51$} & 37.94 & $467 ; 0.13$ & 32.82 & $521 ; 0.33$ & 36.00 & $527 ; 0.11$ \\
\hline & Female & 35.65 & & 34.28 & & 35.49 & & 31.62 & & 35.91 & & 33.24 & \\
\hline \multirow{2}{*}{$\begin{array}{l}\text { Parental } \\
\text { Support }\end{array}$} & Yes & 34.77 & $169 ; 0.62$ & 34.76 & $170 ; 0.68$ & 34.42 & $181 ; 0.87$ & 34.65 & $177 ; 0.82$ & 35.56 & $120 ; 0.03 *$ & 34.35 & $177 ; 0.58$ \\
\hline & No & 31.67 & & 31.83 & & 35.33 & & 33.00 & & 23.50 & & 36.00 & \\
\hline \multirow{2}{*}{\begin{tabular}{|l|} 
Friends \\
support
\end{tabular}} & Yes & 36.39 & $508 ; 0.27$ & 40.33 & $366 ; 0.00^{*}$ & 34.39 & $572 ; 0.94$ & 37.72 & $460 ; 0.10$ & 38.61 & $428 ; 0.01^{*}$ & 35.06 & \\
\hline & No & 32.38 & & 27.94 & & 34.63 & & 30.88 & & 29.88 & & 33.88 & $556 ; 0.50$ \\
\hline \multirow{2}{*}{$\begin{array}{l}\text { Medical } \\
\text { support }\end{array}$} & Yes & 31.90 & $338 ; 0.02 *$ & 33.68 & $427 ; 0.52$ & 33.37 & $410 ; 0.27$ & 34.73 & $454 ; 0.86$ & 34.26 & $453 ; 0.80$ & 33.92 & $437 ; 0.27$ \\
\hline & No & 41.21 & & 36.61 & & 37.42 & & 33.89 & & 35.13 & & 36.00 & \\
\hline
\end{tabular}

${ }^{*} p \leq 0.05 * * p \leq 0.001$

Table 2. Results for the correlational analysis between health perception and adherence.

\begin{tabular}{|c|c|c|c|c|c|c|}
\hline & Diet & Physical activity & Glycemic control & Foot care & Smoking & Insulin administration \\
\hline Functional capacity & $0.24 *$ & $0.25^{*}$ & -0.07 & -0.07 & -0.07 & 0.15 \\
\hline Body pain & 0.10 & -0.01 & 0.02 & 0.16 & -0.01 & 0.09 \\
\hline General health & $0.49 * *$ & 0.23 & $0.27^{*}$ & $0.40 * *$ & -0.00 & 0.14 \\
\hline Vitality & $0.47 * *$ & $0.34 * *$ & -0.07 & $0.35 * *$ & 0.06 & 0.17 \\
\hline Social functioning & $0.33 * *$ & 0.18 & 0.16 & $0.26^{*}$ & -0.04 & 0.10 \\
\hline Physical performance & 0.18 & 0.02 & -0.08 & 0.12 & -0.14 & -0.11 \\
\hline Emotional performance & $0.25^{*}$ & 0.21 & 0.11 & 0.23 & 0.06 & 0.01 \\
\hline
\end{tabular}

$* p \leq 0.05 * * p \leq 0.001$

Considering glycemic control, it can be observed that the only significant obtained value concernsthe general state of health $(r=0.27$; $\mathrm{p}<0.05$ ), which means that adherence to glycemic control increases when participants' general health status increases.

Regarding foot care, positive and significant values were obtained for the general state of health $(r=0.40 ; p<0.001)$, vitality $(r=0.35 ; p$ $<0.001)$, and social aspects $(\mathrm{r}=0.26 ; \mathrm{p}<0.001)$. Thus, it can be observed that adherence to the recommended foot care for diabetic patient's increasesin conjunction with a greater perception of general health, a greater sense of vitality, and greater social performance. No significant values were obtained for smoking and insulin administration.

\section{Discussion}

A review of the literature reveals that there is a poor adherence to therapy among diabetic patients [22]. In this sense, several studies have shown that during adolescence levels of treatment adherence are lower and metabolic control is also worse [23,24]. However, in this study, young people in the sample presented high levels of adherence to diabetes therapy in all of the parameters examined. Thus, while childhood and adolescence are developmental phases marked by the development of different cognitive and social skills that may affect behavior, in relation to compliance with diabetes treatment and metabolic control, in the end these developmental changes may not be that influential [25].

Concerning the relationship between adherence levels and gender differences, some studies show differences in the adherence to diabetes treatment between men and women [26-28]. Yet, in this sample the differences were not statistically significant, which may suggest that gender has no influence on the adherence to the treatment of diabetes. However, female participantspresented higher levels of adherence, and it were also found that the females smoked less than males, contributing to their improved treatment adherence. On the other hand, males recorded higher levels of physical activity, foot care, and drug treatment. These results are concordant with some studies that found higher adherence to drug therapy among males when compared to females [29-31].

Inregards to family support, the results indicate statistically significant differences only between the perception of parental support and smoking. For the remaining dimensions of adherence, the results did not show any statistically significant differences. This is possiblydue to the heterogeneity of the groups where there is a discrepancy in the percentage distribution and whereonly six participant's reportnotreceiving support from their parents. Nevertheless, it was found that young people that perceive tohavesupport from their parents have higher levels of adherence to diet, physical exercise, betterfoot care, and smoke less than those who do not havesuch support. However, young people who do not feel supported by their parents show higher levels of adherence to glycemic control and insulin administration (drug treatment), when compared with young people who reportreceivingsupport from their parents. The latter results may suggest that theperceived support may be negative, inflicting pressure, stress, and anxiety, since positive support is associated with improved metabolic control $[32,33]$. These results may also suggest that young people who do not feelsupportedby theirparents may demonstrategreater autonomy and responsibility concerning their treatment $[34,35]$.

Concerning adherence levels to diet, exercise, and foot care, the results indicate that young people who perceive themselves to have support from their parents, present more of these behaviors and smoke less, which is consistent with other studies [36]. In this sense, family support appears to play a key role in issues pertaining to the adherence and management of therapeutic regimensfor diabetes, by collaborating in carrying out some self-care activities such as monitoring blood glucose, foot care, and medication administration. Social support, 
in particular family support, can be a valuable emotional coping strategythat plays a fundamental role in adherence to therapy and disease control.

Analyzing the relationship between the perception of support from friends and adherence levels, results only show statistically significant differences regarding exercise and smoking habits. A possible explanation for these results is related to the fact that most physical activities involve more than one person, and likely involve one's friends. Thus, it can be assumed that belonging to a friend group that encourages youth to engage in physical activity can be a decisive influence on theadherence to exercise recommendations. Although there are not significant differences for other dimensions, results indicate that young people who feel supported by their friends also have higher levels of adherence to a recommended diet for diabetes, improved foot care, and better adherence to drug treatment (insulin), when compared to those who do not perceive such support.This emphasizes the importanceof one's peer group in adapting to diabetes treatment adherence and clinical development [37].

Regarding the relationship between the perception of medical support and adherence, results only show statistically significant differences concerning diet. Although among all other dimensions of adherence no statistically significant differences were found, we observe that young people who do not perceive to benefit from medical support have higher levels of adherence to physical activity, glycemic control, drug treatment (insulin administration), and smoke less whencompared with those who feel like they receive support from their doctor. These results indicate that medical support does not seem to play a role in adherence to therapy. This can be explained by the fact that the support given by doctorstends to be a negative form of support, with a greater focus on pressure and criticism, rather than praise and the encouragement of positive behaviors.

The importance of studying how young diabetics evaluate their state of health and their treatment adherence is of the foremost importance because it has many implications for all those involved in the process of dealing with the disease. Correlational analysis demonstrates that there is a relationship between the perception that young people have about their health status and their adherence to the treatment of diabetes in its different dimensions. For instance, results indicate that following a recommended diet for diabetes increases levels of functional capacity, general health, social and emotional vitality, and mental health. This was also the case for young people who have a better perception about their general health, who feel more energetic, and who have higher levels of well-being.Therefore, it can be assumed that young people who perceive themselvesas having fewerlimitations in dailyactivities due to a health condition, or as a result of physical and/or emotional problems, show higher levels of adherence to the recommended diet for diabetes.

With regard to the levels of adherence to physical exercise recommendations, we observe that young people who perceivethemselves to have fewer limitations in daily physical activities due to health problems, and who feel more energetic tend to have higher levels of adherence to the recommended exercise for the treatment of diabetes.

Adherence to glycemic control seems to be influenced by the general state of one's health, and the results indicate that a better perception of one's overall health leads to higher levels of adherence to glycemic control. Thus, it appears that young people who have a better perception about their general health tend to have better adherence to the recommended glycemic control for diabetes.

Regarding foot care, the results indicate that ahigher perception of general health, vitality, and social performance are correlated withbetter foot care. Thus, young people who perceivethemselves as enjoying good general health, who have a greater sense of vitality, and who consider themselves to have fewer limitations in usual activities due to physical or emotional problems, tend to have improved foot care.

However, the results concerning the dimensions of adherence to drug treatment and smoking habits indicate that the levels of adherence to these dimensions do not seem to be influenced by any dimension regarding the perception of general health.

Finally, we conclude that the perception that young people have about their general health is related to the levels of adherence to diabetes therapy. Thus, young people who perceive themselves as having fewer limitations, both in daily physical activities due to health problems or due to physical and/or emotional problems, have a better perception of their general health.In addition, greater feelingsof well-being and vitality seem to lead to higher levels of adherence to the recommended prescriptions for diabetic care, namely diet, physical activity, glycemic control, and foot care.

Not many studies about diabetes in adolescents or young adults exist in Portugal, and the scarcity of studies on the perception of health status and its relationto adherenceto treatment and recommendations warrants further research. Despite the fact that this is a relatively small sample, which compromises the generalization of results, this study is an important contribution on which future research can be based.

\section{Implications for clinical practice}

The long-term medical, educational, psycho-emotional, and social effects that occur from daily diabetes management among diabetic youths should be taken into consideration when offering primary care. Prior research has focused on the physiological and not the psychological implications of intensive diabetic treatment programs for adolescents. A better understanding of the challenges faced by adolescents with diabetes will provide a clearer direction to focus future efforts of multidisciplinary, multisystem teamwork by medical professionals.

An important implication of this study is that it demonstrates how the style and quality of medical care can better influence adherence to treatment and behavioral recommendations, given thatclinical research populations of children and youth with diabetes often lack the understanding of relational factors. In addition, given recentadvances in diabetes treatment (e.g., pump therapy), it will be important for future research to examinediabetes care and adherencein relation to specific forms of treatment. Finally, this research suggests that parents and children's agreement to adhereto care regimens varies with the quality of parental support. This information has implicationsfor clinicians when identifying which whether information provided by parents, children, or both should be involved in the assessment of diabetes adherence.

\section{References}

1. SEARCH for Diabetes in Youth Study Group, Liese AD, D'Agostino RB Jr, Hamman RF, Kilgo PD, et al. (2006) The burden of diabetes mellitus among US youth: prevalence estimates from the SEARCH for Diabetes in Youth Study. Pediatrics 118: 1510-1518. [Crossref] 
2. Gardete CL, Boavida JM, Almeida, JPF, Cardoso SM, Dores J, et al. (2013) Diabetes: Facts and Figures 2012. Annual report of the Diabetes Observatory. Lisbon: Portuguese Society of Diabetes.

3. La Greca AM, Schuman W (1995) Adherence to prescribed medical regimens. In: Roberts M (Edr.), Handbook of pediatric psychology, (2nd Edn.), New York: Guilford.

4. Stewart SM, Emslie GJ, Klein D, Haus S, White P (2005) Self-care and glycemic control in adolescents with type 1 diabetes. Children's Health Care 34: 239-244.

5. Diabetes Control and Complications Trial Research Group (DCCTRG) (1994) Effect of intensive diabetes treatment on the development and progression of long-term complications in adolescents with insulin-dependent diabetes mellitus. Journal of Pediatrics 125: 177-188. [Crossref]

6. Burroughs TE, Pontious SL, Santiago JV (1993) The relationship among six psychosocial domains, age, health care adherence, and metabolic control in adolescents with IDDM. Diabetes Educ 19: 396-402. [Crossref]

7. Greening L, Stoppelbein L, Reeves CB (2006) A Model for Promoting Adolescents' Adherence to Treatment for Type 1 Diabetes Mellitus. Children's Health Care 35: 247-267.

8. Ellis DA, Naar-King S, Frey MA, Templin T, Rowland M, et al. (2004) Use of multisystemic therapy to improve regimen adherence among adolescents with type diabetes in poor metabolic control: a pilot study. Journal of Clinical Psychology in Medical Settings 11: 315-324.

9. Patton SR1 (2011) Adherence to diet in youth with type 1 diabetes. J Am Diet Assoc 111: 550-555

10. Wheeler K, Wagaman A, McCord D (2012) Personality traits as predictors of adherence in adolescents with type I diabetes. $J$ Child Adolesc Psychiatr Nurs 25: 6674. [Crossref]

11. Horne R, Weinman J, Barber N, Elliott R, Morgan M, et al. (2005) Concordance, adherence and compliance in medicine-taking. Report for the national coordinatingcentre for NHS service delivery and organization R\&D. London: NCCSDO.

12. Nunes V, Neilson J, O'Flynn N, Calvert N, Kuntze S, et al. (2009) Clinical guidelines and evidence review for medicines adherence: involving patients in decisions about prescribed medicines and supporting adherence. London: National Collaborating Centre for Primary Care and Royal College of General Practitioners.

13. Haynes RB, Ackloo E, Sahota N, McDonald HP, Yao X (2008) Interventions for enhancing medication adherence. Cochrane Database Syst Rev: CD000011. [Crossref]

14. De Civita M1, Dobkin PL (2004) Pediatric adherence as a multidimensional and dynamic construct, involving a triadic partnership. J Pediatr Psychol 29: 157-169. [Crossref]

15. Pereira MG, Almeida AC, Rocha L, Leandro E (2011) Predictors of adherence, metabolic control and quality of life in adolescents with type 1 diabetes. In: Chih-Pin L (Edr.), Type 1 diabetes: Complications, pathogenesis and alternative treatments (Book 3). USA.

16. Grey M, Boland EA, Yu C, Sullivan-Bolyai S, Tamborlane WV (1998) Personal and family factors associated with quality of life in adolescents with diabetes. Diabetes Care 21: 909-914. [Crossref]

17. Emmanouilidou E, Galli-Tsinopoulou A, Karavatos A, Nousia-Arvanitakis S (2008) Quality of life of children and adolescents with diabetes of Northern Greek origin. Hippokratia 12: 168-175. [Crossref]

18. Ware JE, Sherbourne CD (1992) The MOS 36-item short-form health survey (SF-36). Conceptual framework and item selection. Medical Care 30: 473-483. [Crossref]

19. Toobert DJ, Hampson SE, Glasgow RE (2000) The summary of diabetes self-care activities measure: results from 7 studies and a revised scale. Diabetes Care 23: 943950. [Crossref]

20. Gonzalez JS, Delahanty LM, Safren SA, Meigs JB, Grant RW (2008) Differentiating symptoms of depression from diabetes-specific distress: relationships with self-care in type 2 diabetes. Diabetologia 51: 1822-1825. [Crossref]

21. Bastos F, Severo M, Lopes C (2007) [Psychometric analysis of diabetes self-care scale (translated and adapted to Portuguese)]. Acta Med Port 20: 11-20. [Crossref]

22. Silva I, Pais-Ribeiro J, Cardoso H (2006) Adesão ao tratamento da diabetes Mellitus: A importância das características demográficas e clínicas. Revista Referência 2: 33-41.

23. Iannotti RJ, Schneider S, Nansel TR, Haynie DL, Plotnick LP, et al. (2006) Selfefficacy, outcome expectations and diabetes self-management in adolescents with type 1 diabetes. Journal of Developmental and Behavioral Pediatrics 27: 98-105. [Crossref]

24. Danne T, Mortensen HB, Hougaard P, Lynggaard H, Aanstoot HJ, et al. (2001) Persistent differences among centers over 3 years in glycemic control and hypoglycemia in a study of 3,805 children and adolescents with type 1 diabetes from the Hvidore Study Group. Diabetes Care 24: 1342-1347.

25. Griva K, Myers LB, Newman S (2000) Illness perceptions and self-efficacy beliefs in adolescents and young adults with insulin dependent diabetes mellitus. Psychology \& Health 15: 733-750.

26. Enzlin P, Mathieu C, Demyttenaere K (2002) Gender differences in the psychological adjustment to type 1 diabetes mellitus: an explorative study. Patient Educ Couns 48: 139-145. [Crossref]

27. McCollum M, Hansen LS, Lu L, Sullivan PW (2005) Gender differences in diabetes mellitus and effects on self-care activity. Gend Med 2: 246-254. [Crossref]

28. Undén AL, Elofsson S, Andréasson A, Hillered E, Eriksson I, et al. (2008) Gender differences in self-rated health, quality of life, quality of care, and metabolic control in patients with diabetes. Gend Med 5: 162-180. [Crossref]

29. Gimenes HT, Zanetti ML, Haas VJ (2009) Factors related to patient adherence to antidiabetic drug therapy. Rev Lat Am Enfermagem 17: 46-51. [Crossref]

30. Jones JM, Lawson ML, Daneman D, Olmsted MP, Rodin G (2000) Eating disorders in adolescent females with and without type 1 diabetes: cross sectional study. BMJ 320 : 1563-1566. [Crossref]

31. Ciechanowski PS, Katon WJ, Russo JE, Walker EA (2001) The patient-provider relationship: attachment theory and adherence to treatment in diabetes. Am J Psychiatry 158: 29-35. [Crossref]

32. McKelvey J, Waller DA, North AJ, Marks JF, Schreiner B, et al. (1993) Reliability and validity of the Diabetes Family Behavior Scale (DFBS). Diabetes Educ 19: 125-132. [Crossref]

33. Miller VA, Drotar D (2007) Decision-making competence and adherence to treatment in adolescents with diabetes. J Pediatr Psychol 32: 178-188. [Crossref]

34. Silva I, Pais-Ribeiro J, Cardoso H, Ramos H, Carvalhosa S, et al. (2003) Efeitos do apoio social na qualidade de vida, no controlo metabólico e desenvolvimento de complicações crónicas em indivíduos com diabetes. Psicologia,Saúde and Doenças 4: 21-32.

35. Góis C (2002) Aspectos psicosociais do adolescente com diabetes mellitus tipo 1 . Psiquiatria Clínica 23: 63-77.

36. La Greca AM, Bearman KJ (2002) The diabetes social support questionnaire-family version: Evaluating adolescents' diabetes-specific support from family members. Journal of Pediatric Psychology 27: 665-676. [Crossref]

37. Nunes M (2005) Apoio social na diabetes. Millenium: Revista do Instituto Politécnico deViseu 9: 135-149.

Copyright: (C2015 Pereira H. This is an open-access article distributed under the terms of the Creative Commons Attribution License, which permits unrestricted use, distribution, and reproduction in any medium, provided the original author and source are credited. 